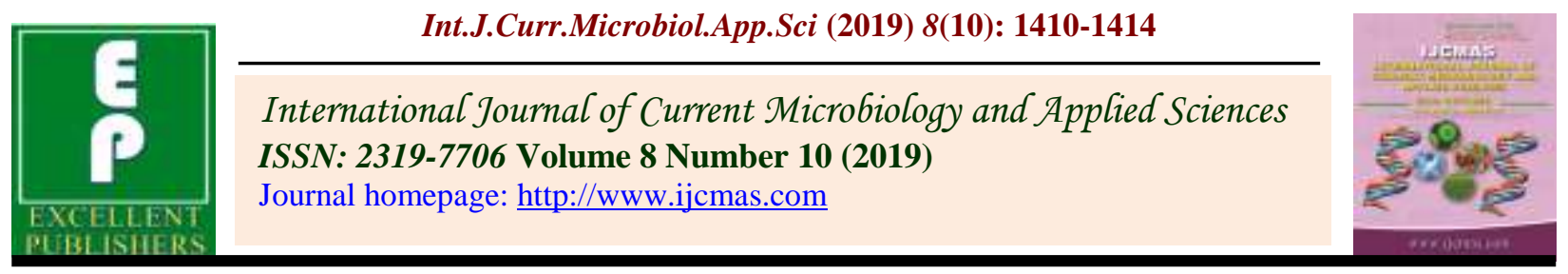

Original Research Article

https://doi.org/10.20546/ijcmas.2019.810.165

\title{
One-Year Prevalence Study of Renal Failure in Canines of Nagpur
}

\author{
G. C. Thade, G. R. Bhojne, V. M. Dhoot, S. V. Upadhye, \\ C. K. Panchbhai and Gurnoor Kaur* \\ Veterinary Clinical Complex, Nagpur Veterinary College, Nagpur, India \\ *Corresponding author
}

\begin{tabular}{|l|}
\hline Ke y w o r d s \\
Renal failure, Dogs, \\
Prevalence, Nagpur
\end{tabular}

A B S T R A C T
There has been a stark difference in the prevalence rates of renal disease throughout the world, due to which prevalence of another region cannot rely upon for reference. The present study was thus aimed at recording the prevalence of renal disease in dogs of Nagpur region with respect to age, sex, breed, stage of presentation and total prevalence. Out of 29,159 dogs presented to TVCC, Nagpur during the one-year study period, 271 dogs $(0.93 \%)$ were recorded to be azotemic. Dogs aged 5 to 10 years and more than 10 years were more affected than dogs younger than 5 years of age. Males were more affected than females. Mixed breeds, Labradors, Pomeranians and German Shepherds were recorded to be most affected. Dogs were most commonly first presented at serum creatinine levels more than $5 \mathrm{mg} / \mathrm{dL}$.

\section{Introduction}

Renal failure in canines has been widely studied throughout the world. The results of prevalence studies have varied in different countries and regions. The variation in the results of these studies could be attributed to change in predisposing factors such as breed, age, sex, environment and nutrition. This study was thus undertaken to help clinicians in early detection of renal failure by specifying the rates of prevalence with respect to various factors.

\section{Materials and Methods}

The study was conducted on dogs presented at the Teaching Veterinary Clinical Complex, Nagpur Veterinary College, Nagpur. Based on history and physical examination, kidney function testing was performed. Dogs having a Serum Creatinine of $>2 \mathrm{mg} / \mathrm{dL}$ and a BUN of $>25 \mathrm{mg} / \mathrm{dL}$ were included in this study. A total of 271 dogs were found to be azotemic based on serum biochemistry values. The hematology was performed using Hematology Analyzer (Horiba Make ABX Micros ESV- 
60)and the serum biochemistry was performed using the Star 21 Biochemical Semi-Auto Analyzer.

\section{Results and Discussion}

In the present study, a total of 29,159 dogs were presented to TVCC over a one-year period from August 2018 to July 2019, of which 271 dogs were noted to be azotemic.

Thus, bringing the total prevalence of kidney disease for a period of one year to $0.93 \%$. A study carried out by Sosnar et al., (2003) noted the total prevalence of renal failure to be $11.9 \%$ over a two-year period. Tufani et al., (2015) in an epidemiological survey to study renal failure in Indian dogs, found the total prevalence to be $1.6 \%$. From the varying results it could be concluded that the prevalence of renal disease varies with the population that is being studied.

The prevalence recorded according to age was highest in the age group of 5-10 years with $44.28 \%$ affected dogs being from this age group, closely followed by dogs aged $>10$ years $(40.96 \%)$. The lowest prevalence was found in $<5$ years aged dogs, with only $14.76 \%$ affected. Nabi et al., (2018) recorded a higher prevalence in dogs aged more than 10 years. The average age of affected dogs regardless of sex was 8.52 years (Table 1 ).

The average age in males was 8.37 years and that in females 8.30 years. The findings of Pelander et al., (2015) also recorded a higher average age in males than females, although the mean age, regardless of sex, was lower. The prominent effect of age on functionality of renal tissue could be attributed to ageassociated degenerative changes in the renal parenchymal architecture.

Out of the 271 dogs, $60.89 \%$ dogs affected were males and $39.11 \%$ were females, thus recording a higher prevalence of renal disease in males (Table 2). The higher prevalence of renal disease in males as compared to females recorded in this study could be accredited to anatomical differences in the size and volume of the male and female kidney and the urogenital system which may play a role in disease progression. Another explanation for the results could be the effect of sex hormones on renal failure. As reviewed by Gavaet al., (2011), in records of animal model studies carried out, oestrogen is shown to have a protective effect over kidneys by inhibiting RAAS, reducing glomerulosclerosis, reducing oxidative stress and slowing the progression of renal failure. Testosterone, on the other hand, is responsible for inducing RAAS. The results could also be attributed to preference of owners to keep male dogs as pets. O'Neill et al., (2013) found the prevalence in male dogs to be slightly higher than female dogs in a survey carried out in the UK.

The breeds most commonly affected were Mixed-breed dogs (27.67\%), Labrador retriever (25.09\%), Pomeranian (13.28\%), German shepherd (9.59\%), Spitz (9.59\%), Golden retriever (2.95\%), Dalmatian $(2.21 \%)$, Rottweiler (1.85\%) and Pug (1.85\%), Doberman pinscher (1.48\%), and Saint Bernard (1.11\%) (Table 3). Beagle, Dachshund and Lhasa Apso breeds showed an equal prevalence at $0.74 \%$. The lowest prevalence was recorded in Great Dane, Boxer and Shih Tzu at $0.37 \%$. Athaley (2018) recorded a similar prevalence in Pomeranians and Labradors in a study carried out in the same region, pointing towards preference to keep certain breeds as pets in this region, resulting in their higher representation in the population. The higher prevalence of renal failure in Mixed breed dogs could be explained by their numbers being more in the total dog population due to unsupervised breeding and lack of birth control programmes in Nagpur city. 
Table.1 Age-wise prevalence of renal failure in dogs

\begin{tabular}{|c|c|c|}
\hline Age & $\mathbf{n}$ & $\%$ \\
\hline$<5$ years & 40 & 14.76 \\
\hline 5-10 Years & 120 & 44.28 \\
\hline$>10$ years & 111 & 40.96 \\
\hline
\end{tabular}

Table.2 Sex-wise prevalence of renal failure in dogs

\begin{tabular}{|c|c|c|}
\hline Sex & n & \% \\
\hline Male & 165 & 60.89 \\
\hline Female & 106 & 39.11 \\
\hline
\end{tabular}

Table.3 Breed-wise prevalence of renal failure in dogs

\begin{tabular}{|c|c|c|}
\hline Breed & N & \% \\
\hline Mixed Breed & 75 & 27.67 \\
\hline $\begin{array}{c}\text { Labrador } \\
\text { Retriever }\end{array}$ & 68 & 25.09 \\
\hline $\begin{array}{c}\text { Pomeranian } \\
\text { German } \\
\text { shepherd }\end{array}$ & 36 & 13.28 \\
\hline Spitz & 26 & 9.59 \\
\hline Golden retriever & 8 & 9.59 \\
\hline Dalmatian & 6 & 2.95 \\
\hline Rottweiler & 5 & 2.21 \\
\hline Pug & 5 & 1.85 \\
\hline Doberman & 4 & 1.85 \\
\hline pinscher & & 1.48 \\
\hline Saint Bernard & 3 & 1.11 \\
\hline Beagle & 2 & 0.74 \\
\hline Dachshund & 2 & 0.74 \\
\hline Lhasa Apso & 2 & 0.74 \\
\hline Great Dane & 1 & 0.37 \\
\hline Boxer & 1 & 0.37 \\
\hline ShihTzu & 1 & 0.37 \\
\hline Total & 271 & 100.00 \\
\hline & & \\
\hline
\end{tabular}

Table.4 Prevalence of renal failure in dogs according to serum creatinine levels

\begin{tabular}{|c|c|c|}
\hline $\begin{array}{c}\text { Serum } \\
\text { Creatinine } \\
\text { (mg/dL) }\end{array}$ & n & \% \\
\hline $\begin{array}{c}\text { More than 2 } \\
\text { and below 5 }\end{array}$ & 115 & 42.44 \\
\hline 5-10 & 79 & 29.15 \\
\hline More than 10 & 77 & 28.41 \\
\hline
\end{tabular}


With regards to the stage of presentation, of a total of $271 \mathrm{dogs}, 42.44 \%$ dogs were presented with a serum creatinine ranging between more than 2 and less than $5 \mathrm{mg} / \mathrm{dL}$, whereas $29.15 \%$ dogs were presented with a serum creatinine between 5 to $10 \mathrm{mg} / \mathrm{dL}$ and the number of dogs presented with a serum creatinine of more than $10 \mathrm{mg} / \mathrm{dL}$ was $28.41 \%$ (Table 4). Similar findings were recorded by Sharma et al., (2015) and Ramesh et al., (2018), where the highest percentage of azotemic dogs were noted to be in Stage 3 and 4 of chronic kidney disease at the time of presentation. Advanced stages of disease at the time of presentation could be attributed to undiagnosed acute renal failure, improper management and asymptomatic renal disease progression.

The total prevalence of kidney disease was thus found to be $0.93 \%$. Dogs older than 5 years of age were majorly affected with renal disease $(85.24 \%)$, with similar representation of dogs between 5 to 10 years and dogs older than 10 years. Males were found to have a higher incidence of renal disease (60.89\%) than females (39.11\%). Dogs recorded to have the highest percentages were of Mixed breeds, followed by Labrador retrievers, Pomeranians and German Shepherds while other breeds were less affected. Dogs were most commonly presented at advanced stages of kidney disease, with highest representation being at serum creatinine levels of $>5 \mathrm{mg} / \mathrm{dL}(57.56 \%)$, followed by levels of 2 to $5 \mathrm{mg} / \mathrm{dL}(42.44 \%)$.

\section{References}

Sosnar, M., Kohout, P., Ruzicka, M. and Vrbasova, L. (2003) Retrospective Study of Renal Failure in Dogs and Cats Admitted to University of Veterinary and Pharmaceutical Sciences Brno during 1999-2001 Acta Vet. Brno, 72: 593-598.

Tufani, N. A., Singh, J. L., Kumar, M., Gupta,
D., Shekhar, P. and Rajora, V.S. (2015) Renal failure in Indian dogs: An epidemiological study. Indian J. Vet. Med. Vol. 35, No. 1: 7-11.

Nabi, S. U., Dey, S., Shah, O. S., Hussain, T., Amin, U., Vala, J., Jan, A., Ramdas, A. G., Muhee, A., Hussain, A. and Beigh S. A. (2018) Incidence of renal disorders in canines and its relation with age breed and sex. The Pharma Innovation Journal; 7(1): 87-89.

Pelander, L., Ljungvall, I., Egenvall, A., Syme, H., Elliott, J. and Häggström, J. (2015) Incidence of and mortality from kidney disease in over 600,000 insured Swedish dogs. Vet Rec. 2015 Jun 20; 176(25): 656.

Gava, A. L., Freitas, F. P. S., Meyrelles, S. S., Silva, I. V. and Graceli, J. B. (2011) Gender-dependent effects of ageing on the kidney. Braz J Med Biol Res 44(9): 905-913.

O’Neill, D.G., Elliott, J., Church, D.B., McGreevy, P.D., Thomson, P.C. and Brodbelt, D.C. (2013) Chronic Kidney Disease in Dogs in UK Veterinary Practices: Prevalence, Risk Factors, and Survival. J Vet Intern Med; 27: 814-821.

Athaley, A. J. (2018) Comparative therapeutic efficacy of polyherbal combinations in renal failure in dogs. Unpublished $\mathrm{M}$. V. Sc. Thesis submitted to Maharashtra Animal and Fishery Sciences University, Nagpur.

Bhojne, G. R., Dakshinkar, N. P., Kothekar, M. D., Kurkure, N. V., Dhoot, V. M., Upadhye, S. V. and Thakur, K. (2016) Prevalence of Renal Insufficiency in Dogs of Nagpur City. Indian Journal of Canine Practice, Vol. 8 Issue 2: 107 110.

Sharma, A., Ahuja, A., Srivastava, M. and Kachhawa, J. P. (2015) HaematoBiochemical Changes in Dogs 
Suffering from Chronic Renal Failure. Indian Journal of Canine Practice Volume 7 Issue 2, December: 102-107.

Ramesh, P., Sumathi, D., Gopalakrishnan, A., Vairamuthu, S. and Jayathangaraj,
M.G. (2018) Hemato-Biochemical Evaluation - A Prognostic Tool for Chronic Kidney Disease (CKD) in Canines. Intas Polivet. Vol. 19 (II): 217-219.

\section{How to cite this article:}

Thade, G. C., G. R. Bhojne, V. M. Dhoot, S. V. Upadhye, C. K. Panchbhai and Gurnoor Kaur. 2019. One-Year Prevalence Study of Renal Failure in Canines of Nagpur. Int.J.Curr.Microbiol.App.Sci. 8(10): 1410-1414. doi: https://doi.org/10.20546/ijcmas.2019.810.165 